\title{
Smart Autonomous Wheelchair Controlled by Voice Commands-Aided by Tracking System
}

\author{
Farah F. Alkhalid ${ }^{1}$, Bashra Kadhim Oleiwi ${ }^{2}$ \\ $1 \& 2$ Control and Systems Engineering Department/ University of Technology_Baghdad, IRAQ \\ 10352@uotechnology.edu.iq1 ,60010@uotechnology.edu.iq
}

\begin{abstract}
This study focuses on the design of an autonomous wheelchair based smart driving features for disabled persons. The movement directions and position tracking of the wheelchair are controlled and localized by pre-defined voice commands and global positioning system (GPS), respectively. Arduino microcontroller based on speaker dependent voice recognition module and tracking system based on quad-board SIM808 has been used to help the wheelchair navigation. The experimental tests of the proposed system have been done and given satisfactory results in controlling the wheelchair and making a call on demand. Hence the proposed system is a simple, easy to use and lowcost hardware for designing.
\end{abstract}

Index Terms-Wheelchair tracking system, Arduino UNO, a voice recognition module, SIM808 module, GPS.

\section{INTRODUCTION}

The wheelchair is an important assistance tool to help the mobility of people suffering from multiple types of disabilities. From the earliest manual wheelchairs to their modern electric counterparts, a considerable amount of research and development have been devoted to improving autonomy in mobility. Other developments, such as advances in the Internet, have developed the concept of Internet Objects. This is a promising area that has been studied to improve the mobility independence of the electrical wheelchairs by enabling autonomous navigation and avoiding obstacle [1,2]. Through many research projects in this field, different solutions introduced, such as the user can control the wheelchair via touchscreens [3] and voice commands [4-8]. For instance, [5, 6] used the android application in the mobile device and voice- recognition system. Arduino kit microcontroller circuit, DC motors, and IR sensors have been used to control wheelchair movement and to detect the obstacles in the way. While Arduino microcontroller and speaker dependent voice recognition processor has been used on [7] to support the navigation of the wheelchair. Thus, the direction and velocity of the chair have been controlled by predefined Arabic voice commands. Besides these, wheelchair control is also possible by eye movement [9-10], thus, the camera and Raspberry Pi board have been used to control of wheelchair system operation using the camera to track the location of eye pupil based on image processing technique. Thus, the ultrasonic sensor is also used for static or mobile obstacle detection. In addition, the wheelchair is controlled by head motion [11] which proposed a head motion recognition algorithm using accelerometer data. The wheelchair joystick controlled based on the system's mechanical actuator. While [12] used joystick mode, accelerometer mode, an ultrasonic and infrared sensor system for the wheelchair. [13] proposed the movement control system by a camera fixed on the wheelchair. The patient's hand movements are recognized using a visual recognition algorithm through the 
recurrent neural network. [14] used Raspberry PI based voice, ocular movements, and global pos+52itioning system. In this paper, we extended our model in [15, 16] to control wheelchair movements in different directions using the voice commands of a disabled person and track its position using a tracking system. In other words, this study combined voice recognition system and tracking system in the wheelchair.

The rest of this paper is organized as follows. Section II focuses on the proposed model with its detailed description and explanations. Section III summarizes the hardware that embedded in the system and the section IV represents the implementation of the proposed system and discusses the obtained results. The last section shows the conclusion of the proposed implementation.

\section{THE PROPOSED MODEL}

Basically, this system has consisted of two parts one for driving a wheelchair and the other components for controlling and tracking it. The system has been controlled by voice commands which have saved in voice recognition module. where the disabled person has to prepare and save his orders as a voice command in order to manage his wheelchair. The commands are controlling the driving wheelchair in different directions (moving Forward, backward, turn left, turn right and stop), adjusting the seat (straight forward, straight backward, raise a leg and set down the leg) and make calls. In addition, this system provided with a tracking device which sends SMS with coordinates of the wheelchair in order to denote the position of the disabled person. The disabled person can easily say "forward" so the wheelchair would move forward till the disabled order it to "stop". Moreover, the disabled can make a call on demand to a specific phone number to ask help or any other reason, and can anyone sends SMS to a wheelchair to get it location at the moment, Fig. 1 shows the diagram of possibilities of this system.

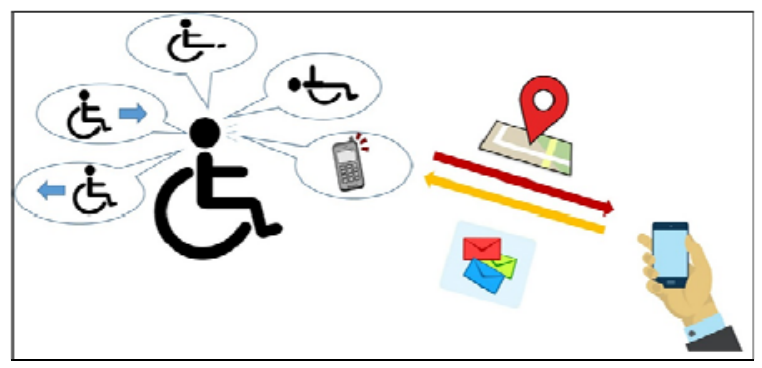

FIG. 1. GENERAL DIAGRAM OF THE PROPOSED SYSTEM.

The mechanism of the sequence of system operation is briefly described in the flowchart shown in Fig. 2.

The system mentioned above as denoted in Fig. 2, will be trained with several predefined voice commands in order to fix the standard instructions. Thus, the system will listen via the mic all the time and whenever sensed a predefined voice command, the desired task will be implemented. The proposed system consists of Arduino UNO, DC motors, quad-board SIM 808, and servo motors voice recognition module, batteries, and jumpers. 


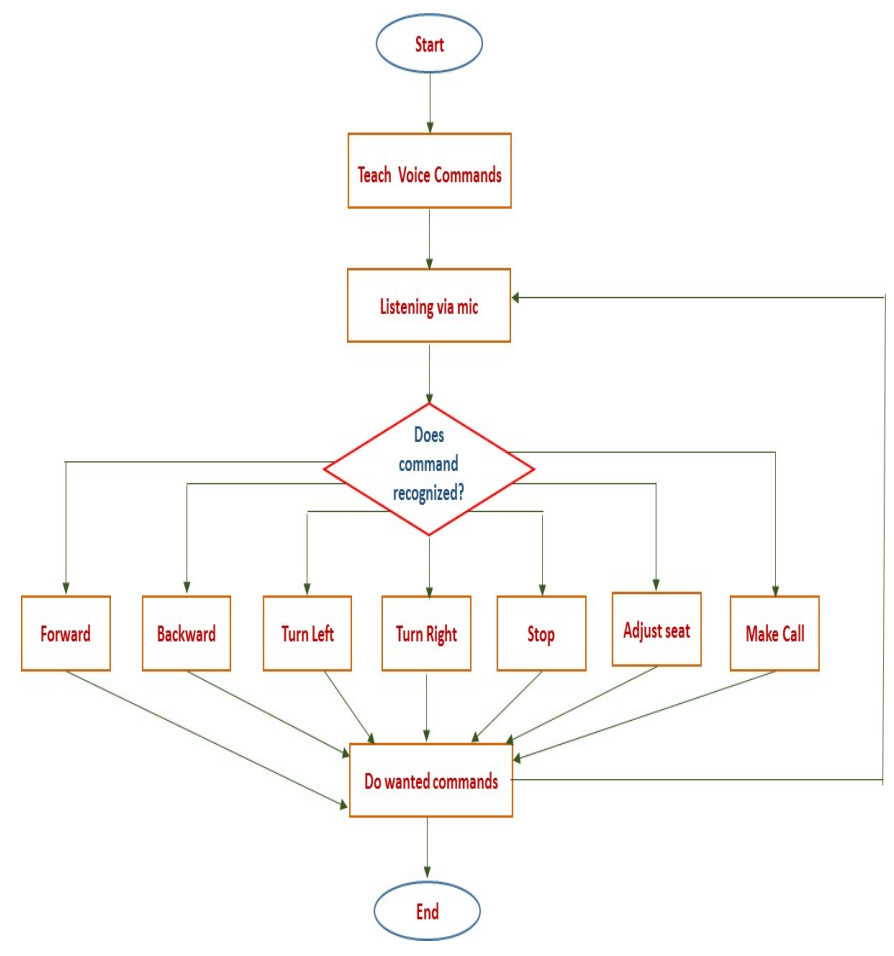

FIG. 2. FLOWCHART OF THE PROPOSED SYSTEM.

The main hardware components were used in this system are:

\section{A. Arduino UNO Board}

As can be seen in Fig. 3, it is a microcontroller board which consists of fourteen digital pins used as input/output (six pins can be used as PWM outputs), six analog inputs, a sixteen MHz ceramic resonator, a USB port for connection [17] needs five volts to operate.

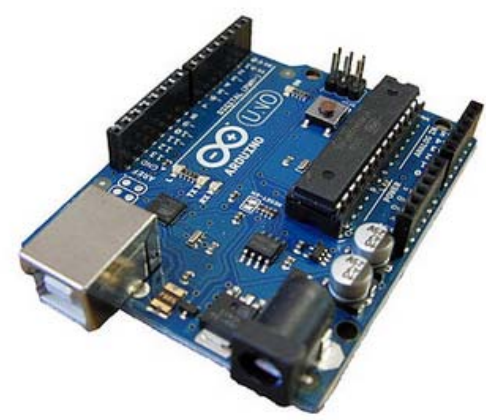

Fig. 3. ARduino UNO BOARD.

\section{B. Voice Recognition Module}

It is a speaker-dependent voice recognition module. It supports up to 80 voice commands in all. Max 7 voice commands could work at the same time. Any sound could be trained as a command. Users need to train the module first before let it recognizing any voice command, with each voice $1500 \mathrm{~ms}$ (one or two words speaking) runs with $4.5 \mathrm{~V}-5.5 \mathrm{~V}$ [18], Fig. 4 shows this module. 


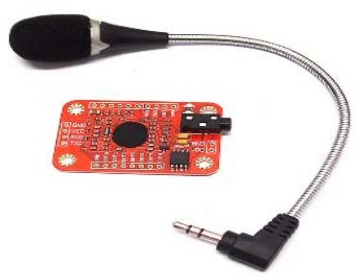

FIG. 4. VOICE RECOGNITION MODULE.

\section{Sim808 Module}

SIM808 module is a GSM and GPS two-in-one function module. It is based on the latest GSM/GPS module SIM808 from SIMCOM, supports GSM/GPRS quad-band network and combines GPS technology for satellite navigation input voltage is 5V [19].

\section{EXPERIMENTAL RESULTS}

The experimental results are being presented in this section. Thus, a complete hardware wiring of the proposed system described in Fig. 5 and Fig. 6 and it is ready to use, as illustrated in TABLE 1 and TABLE 2.

TABLE 1. ARDUINO UNO - SIM 808 WIRING

\begin{tabular}{cc}
\hline Arduino Uno & SIM 808 \\
\hline GND & GND \\
$5 \mathrm{~V}$. & VCC \\
Pin 3 & RXD \\
Pin 2 & TXD \\
\hline
\end{tabular}

TABle 2. ARduino Uno - Voice ReCognition Module Wiring

\begin{tabular}{cc}
\hline Arduino Uno & Voice Recognition Module \\
\hline GND & GND \\
$5 \mathrm{~V}$. & VCC \\
Pin 10 & RXD \\
Pin 11 & TXD \\
\hline
\end{tabular}

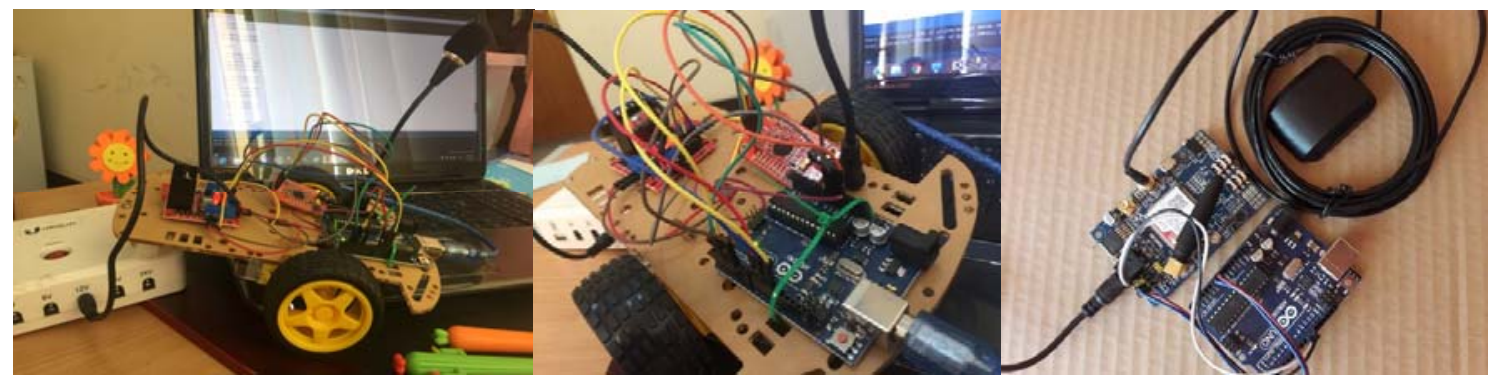

(a)

(b)

(c)

Fig. 5. FinAl DESigned SySTEM, (A) AND (B) Voice RECOGNITION SYSTEM (C) WHEELCHAiR TRACKing SySTEM

The first part of the system which is Arduino based voice recognition device has been embedded inside wheelchair and operated by different commands to move forward, backward, turn left, turn right and stop, the system obeyed simultaneously with an accepted delay not exceeded $(500 \mathrm{~ms})$. This delay is because each voice command needs (1500 ms) to recognize the order, so if the order is less than this duration, an accepted delay will be 
sensed. The second part of the system about track the wheelchair position is moduled, as can be observed in Fig. 6 illustrates the requested SMS from a user and the replied SMS of current location coordinates from the tracking device has been demonstrated in Fig. 6-a. Moreover, Fig. 6-b shows the location of the wheelchair on a cell phone as defined by longitude and latitude. Fig. 6-c depicts the google map with the current location obtained using the wheelchair tracking device. Thus, the bubble indicates the wheelchair location in term of latitude and longitude coordinates. The testing place was in the building whose longitude and latitude as shown.

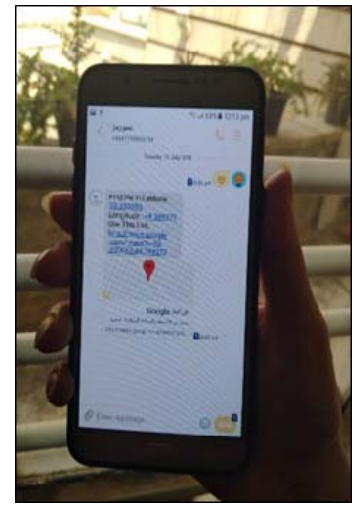

(a)

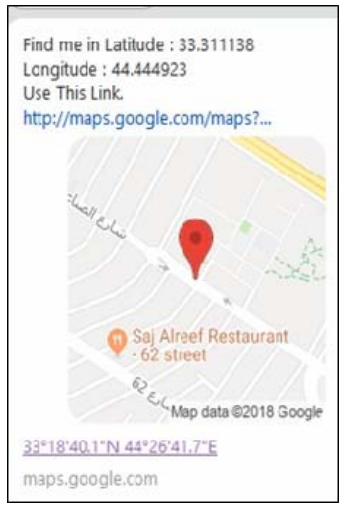

(b)

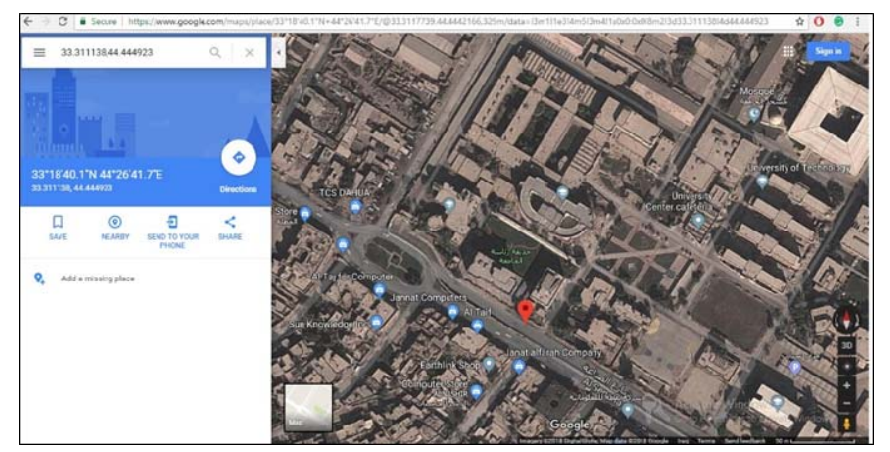

(c)

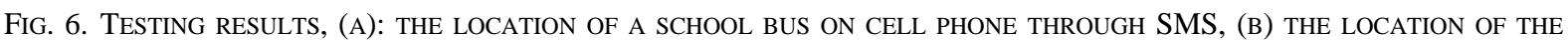
SCHOOL BUS ON THE GOOGLE MAP, (C) SATELLITE GOOGLE MAP.

\section{CONCLUSION}

The main focus of the proposed system is to facilitate and increase the mobility of disabled people. The proposed system has been successfully designed and implemented, for most of the commands the voice recognition system worked to drive a wheelchair and suit the seat adjustment by predefined voice commands. In addition, the possibility of reaching a wheelchair position any time easily. The proposed system has been tested by different persons in different noisy environments and proven its robustness and given very exciting results. It's worth to mention that the proposed system is a simple, easy to use and inexpensive hardware for implementing.

\section{ACKNOWLEDGMENT}

The authors gratefully acknowledge Prof. Jawad K. Ali, Department of Electrical Engineering, the University of Technology, Baghdad- Iraq for his invaluable help and support which helped us a lot in successfully completing our research. 


\section{REFERENCES}

[1] U. Cortes, C. Urdiales, R. Annicchiarico, C. Barrue, A.B. Martinez, C. Caltagirone: assistive Wheelchairnavigation: A cognitive vView, Studies in Computational Intelligence: Advanced Computational Intelligence Paradigms in Healthcare - 1, vol. 48, pp. 165 - 187, 2007.

[2] S. Sheikh, A. Sheikh, A.Waghmare, A. Yadav, S. hubhamBhoyar, C. hetanadolase "Design and construction of electric drive -A smart system for a disabled person with therapy facilities, International Research Journal of Engineering and Technology (IRJET), vol. 05, issue03, 2018.

[3] J. L. Jaffe, A Case study: The ultrasonic head controlled wheelchair and interface, OnCenter: Technology Transfer News, vol. 1, no. 2, 1990.

[4] R.C. Simpson, S.P. Levine, "Voice control of a powered wheelchair", IEEE Transactions on Neural Systems and Rehabilitation Engineering, vol. 10, no. 2, pp. 122 - 125, 2002.

[5] R. Bhardwaj, P. Gupta, P.Jadhav, B. Kadam, A.Kedari, Android-based automated smart wheelchair, International Journal of Innovative Research in Computer and Communication Engineering, vol. 4, issue 3, 2016.

[6] A. A. Abed, Design of voice-controlled a smart wheelchair, International Journal of Computer Applications (0975 8887) vol. 131, no.1, 2015.

[7] M. I. Malik, T. Bashir, O. F. Khan, Voice controlled wheelchair system, International Journal of Computer Science and Mobile Computing, Vol.6 Issue.6, pg. 411-419, 2017.

[8] S. N. Patel, V. Prakash, Autonomous camera-based eye-controlled wheelchair system using Raspberry-Pi, IEEE Sponsored 2nd International Conference on Innovations in Information Embedded and Communication Systems, ICIIECS'15, 2015.

[9] D.Sahu, Automatic camera-based eye-controlled wheelchair system using Raspberry Pi, International Journal of Science, Engineering and Technology Research (IJSETR), vol. 5, issue 1, 2016.

[10] P. Harsh, S. Daivik, P. Pranay, V. Rudri, M. Patel, Intelligent assistant system, IJSRD - International Journal for Scientific Research \& Development| vol. 4, issue 09, 2016, ISSN (online): 2321-0613.

[11] A. Radmanovic, B. Dokic, Wheelchair control by head motion, Serbian Journal of Electrical Engineering, vol. 10, no. 1, pp. 135-151, 2013.

[12] P.Gokulsrinath, A.Koilraj, K. B Kumar, R. Arun, R. Dharmadurai, Intelligent wheelchair for handicap people, International Journal for Research in Applied Science \& Engineering Technology (IJRASET), vol. 5, issue III, 2017.

[13] Y. Rabhi, M. Mrabet, and F. Fnaiech, Intelligent control wheelchair using a new visual joystick, Journal of Healthcare Engineering, vol. 2018, Article ID 6083565, https://doi.org/10.1155/2018/6083565, 2018.

[14] G. Manjunath, Autonomous wheelchair with a smart driving mode and a Wi-Fi positioning system, Master thesis in Computer Engineering - Mobile Computing at the School of Technology and Management of the Polytechnic Institute of Leiria.

[15] Farah F. Alkhalid, Bashra Kadhim Oleiwi, Abdul Muhsin M., Schoolbus tracking device through determination geographical location, Jour of Adv Research in Dynamical \& Control Systems, vol. 10, 06-Special issue, 2018.

[16] Bashra Kadhim Oleiwi, Farah F. Alkhalid, Handicapped Voice Recognition Control System based on HMM Algorithm, International Journal of Mechanical Engineering and Technology (IJMET), vol. 9, Issue 11, November 2018, pp. 1071-1079, Article ID: IJMET_09_11_110

[17] Arduino UNO datasheet, https://datasheet.octopart.com/A000066-Arduino-datasheet-38879526.pdf

[18] Voice recognition module, last seen 1/9/2018, [online] Available: https://www.elechouse.com/elechouse/images/product/VR3/VR3_manual.pdf.

[19] Sim808 datasheet, last seen 1/9/2018, [online] Available: https://cdnshop.adafruit.com/datasheets/SIM808_Hardware+Design_V1.00.pdf. 